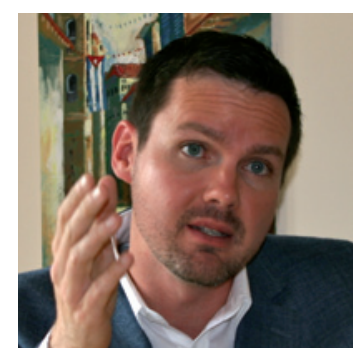

\title{
Researchers can't regulate climate engineering alone
} Political interests, not scientists or inventors, will be the biggest influence on technologies to counter climate change, says Jason Blackstock.

$\mathrm{S}$ cientists are developing geoengineering technologies. But whether these methods eventually succeed in countering climate change, and whether they will be embraced by the wider population, concerns more than scientists alone. That is why, in the wake of the cancellation last month of the Stratospheric Particle Injection for Climate Engineering (SPICE) field trial and the attendant publicity, it is important that the correct lessons are drawn by scientists, funders, regulators and politicians alike.

In an Editorial about SPICE, this publication pointed out that geoengineers must "grasp the nettle of regulation and oversight" (see Nature 485, 415; 2012). It added that community-proposed guidelines such as the Oxford Principles need practical implementation frameworks to make an impact. Both issues do demand urgent attention, but there is a more important consideration: something that geoengineers coming together to "draft detailed, practical actions", as the Editorial recommended, simply cannot address. Geoengineering will alter the geopolitics of climate change and this cannot be ignored by climate policy-makers.

SPICE turned the focus of the geoengineering debate onto patenting and concerns that personal or corporate ownership could take precedence over global public interest. But patents are far from the biggest issue for techniques such as solar geoengineering (blocking the Sun's radiation, as investigated by the SPICE project).

The cost of injecting enough aerosols into the stratosphere to counter the warming projected for even high-emission scenarios is estimated to be only about US\$1 billion per year. That amounts to less than $\$ 0.01$ per year to compensate for each tonne of carbon dioxide emitted. And most of the necessary technology exists already, such as high-altitude aircraft (of which only a couple of dozen would be needed). Inventors of solar-geoengineering methods might try to charge large sums to license patents on their ideas, but this will not create a lucrative new industry for large corporations.

That said, existing industries, especially agriculture and energy, will have a strong interest in whether and when solar geoengineering is used, given that these methods could have sweeping effects on climate, both desirable and undesirable. But industry influence will occur much more through political lobbying than through patent ownership.

At present, the power in climate negotiations is squarely in the hands of the major carbon-emitting nations. Technically, a coalition of vulnerable nations - say, low-lying island states threatened by rising seas - might be able to muster $\$ 1$ billion per year to reverse global warming, but the potential game-changer when it comes to geoengineering is not technical assessments, but

\section{NATURE.COM}

Discuss this article online at:

go.nature.com/ws6bxs geopolitical calculations. We scientists know this. We have consulted with civil society, the private sector and government officials through the 2010 Asilomar Conference in California - which worked on policy recommendations for geoengineering - and the ongoing Solar Radiation Management Governance Initiative launched by the Royal Society in London. Both have indicated the need for action beyond geoengineering researchers. But if assembling these groups has not yet generated the necessary 'practical actions', then what will?

Geoengineering researchers can experiment with ways to translate guidelines into a practical regulatory framework, beginning with a voluntary registry of ongoing and planned research. But responsibility also rests with funders. More research is needed to ensure that we understand the abilities and limits of solar-geoengineering technology before it is deployed in political desperation. It would be a tragedy if the negative publicity around SPICE scared funds away from this work. Funders can also help to establish norms of international cooperation. First steps would include creating incentives for collaboration on research, and sharing lessons on how to responsibly oversee and monitor controversial projects.

Ultimately, climate policy-makers need to get involved. Current international institutions are simply not prepared for geoengineering. Discussing solar geoengineering at the United Nations climate talks now would only disrupt progress towards the already ambitious goal of agreeing a global mitigation and adaptation strategy by 2015. And the Convention on Biological Diversity, the only international body yet to tackle the issue of solar geoengineering directly, has neither the mandate nor sufficient political clout to broker a geopolitical agreement.

Climate negotiators and political leaders need to develop strategies to fill the governance gap. They also need to consider the signals that domestic funding of geoengineering research sends about future climate-policy intentions. Failure to come to grips with these issues could lead to problems if events such as geoengineering field experiments outpace political preparations.

Greater political engagement may be uncomfortable for climate scientists. Climate science has fought hard to resist agendas that force particular research or conclusions. But such agendas - both corporate and national - do influence climate policy, and geoengineering technologies could magnify that influence. Politics can't be avoided, and ignoring it is dangerous for all of us.

Jason Blackstock is a visiting fellow with the Institute for Science, Innovation and Society at the University of Oxford, UK.

e-mail:jason.blackstock@insis.ox.ac.uk 